This article was downloaded by: [Catherine Ann Cameron]

On: 26 June 2013, At: 02:28

Publisher: Routledge

Informa Ltd Registered in England and Wales Registered Number: 1072954 Registered

office: Mortimer House, 37-41 Mortimer Street, London W1T 3J H, UK

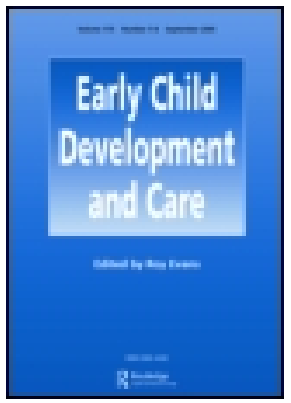

\title{
Early Child Development and Care
}

Publication details, including instructions for authors and subscription information:

http:// www. tandfonline.com/loi/gecd20

\section{Exploring transactions between thriving toddler girls and their fathers and grandfathers}

Catherine Ann Cameron ${ }^{a}$, Giuliana Pinto ${ }^{b}$, Roger Hancock ${ }^{c} \&$ Sombat Tapanya ${ }^{d}$

a Psychology Department, University of British Columbia , 2136 West Mall, Vancouver, British Columbia , Canada, V6T $1 Z 4$

b Psychology Department, University of Florence, Florence 93 , Italy

${ }^{c}$ Education and Language Studies, Open University, Milton, Keynes, UK

d Department of Psychiatry , Chiang Mai University , Chiang Mai , Thailand

Published online: 26 J un 2013.

To cite this article: Catherine Ann Cameron, Giuliana Pinto, Roger Hancock \& Sombat Tapanya (2013): Exploring transactions between thriving toddler girls and their fathers and grandfathers, Early Child Development and Care, DOI: 10.1080/ 03004430.2013.806494

To link to this article: http:// dx.doi.org/ 10.1080/ 03004430.2013.806494

\section{PLEASE SCROLL DOWN FOR ARTICLE}

Full terms and conditions of use: http://www.tandfonline.com/page/terms-andconditions

This article may be used for research, teaching, and private study purposes. Any substantial or systematic reproduction, redistribution, reselling, loan, sub-licensing, systematic supply, or distribution in any form to anyone is expressly forbidden.

The publisher does not give any warranty express or implied or make any representation that the contents will be complete or accurate or up to date. The accuracy of any instructions, formulae, and drug doses should be independently verified with primary sources. The publisher shall not be liable for any loss, actions, claims, proceedings, 


\title{
Exploring transactions between thriving toddler girls and their fathers and grandfathers
}

\author{
Catherine Ann Cameron ${ }^{\mathrm{a} *}$, Giuliana Pinto ${ }^{\mathrm{b}}$, Roger Hancock ${ }^{\mathrm{c} \dagger}$ and \\ Sombat Tapanya ${ }^{\mathrm{d}}$
}

${ }^{a}$ Psychology Department, University of British Columbia, 2136 West Mall, Vancouver, British Columbia, Canada V6T 1Z4; ${ }^{5}$ Psychology Department, University of Florence, Florence 93, Italy; ${ }^{c}$ Education and Language Studies, Open University, Milton Keynes, UK; ${ }^{d}$ Department of Psychiatry, Chiang Mai University, Chiang Mai, Thailand

(Received 5 March 2013; final version received 14 May 2013)

\begin{abstract}
Fathers' interactions with their young children are understudied. Variations between families in the masculine nurturance of toddlers can be expected, depending on personal characteristics, gender, family structures, and cultural contexts in which they are situated. This is a qualitative study, focusing on probing the nature of the exchanges between female toddlers and their male caregivers, to gain an understanding of the dynamic nature of these interchanges. We observed four thriving 30-month-old girls in Italy, the UK, Peru, and Thailand, wherein filmed transactions between them and their fathers and grandfathers during one Day in their Lives were observed, documented, and analysed. The case studies of these young girls demonstrated considerable agency in their interactions with their caregivers, which were, in part, responsible for a wide range of promotive nurturance styles in the adults.
\end{abstract}

Keywords: fathers; grandfathers; toddlers; transactions; agency; thriving

Fathers of preschoolers are not so well studied as mothers, and are sometimes undervalued as a force in healthy family functioning (Amato, 1998; Harmon \& Perry, 2011). Saracho and Spodek (2008) delineated certain conceptual and methodological problems in earlier investigations of fathers' family roles and labelled fathers "'invisible" parents'. Fathers most notably contribute to the economic well-being of their families (Lamb, 2010); they model morals (Parke, 1996), encourage persistence (Padilla-Walker, Day, Dyer, \& Black, 2013), perceptions of acceptance (Khaleque \& Rohner, 2012), contribute to gender schemata (Tenenbaum \& Leaper, 2002); and engage their children in 'rough and tumble activities' (Fletcher, 2008; Fletcher \& Visser, 2008). Indeed, they famously play and communicate actively with their children (Pancsofar \& Vernon-Feagans, 2010). However, what other roles in nurturance do they serve in the lives of their very young children?

Since the 1970s and such pioneering research as that of Clarke-Stewart (1978) many studies have investigated fathers' direct and indirect parental roles with respect to their partners and their children. Lamb and colleagues (Lamb, 2010; Lewis \& Lamb, 2006) have investigated fatherhood from many important perspectives in recent decades but

${ }^{*}$ Corresponding author. Email: acameron@psych.ubc.ca
${ }^{\dagger}$ Current address: 28 Haslemere Road, Crouch End, London N89RB, UK. 
there is still much to learn about fathers, as the preponderance or research on childrearing and child socialisation often remains focused on the contributions of mothers, and especially the mothers of very young children (Newland \& Coyl, 2010; Van Dijken, Van Der Veer, Van IJzendoorn, \& Kuipers, 1998). Furthermore, recent advances in neuroscience and comparative biology have extended understanding of sources of mediation in fathers' interactions with their young. Decrements in testosterone and increments in oxytocin have been documented with human fathers of newborns (Gettler, McDade, Feranil, \& Kuzawa, 2011) and recent studies have established the role of hormonal influences and stress on paternal nurturance in other mammals as well (de Jong, Korosi, Harris, Perea-Roderigues, \& Saltzman, 2012).

Boyce et al. (2005), in a longitudinal study of well-being, reported that father involvement in infant care moderates susceptibility to bio-behavioural social-stress reactivity in middle childhood and that stress vulnerability is exacerbated by maternal depression. Boyce et al. also reported girls of uninvolved fathers to exhibit troubled internalising responses and fathers were hypothesised as sources of both sexual dimorphism in biological circuitry and gender constraints on expression of psychological distress. Pougnet, Serbin, Stack, and Schwartzman (2011) recently reported a prospective longitudinal study of fathers and their children in middle childhood and then again in preadolescence wherein father presence in middle childhood predicted fewer internalising problems in girls three to five years later and higher-rated performance-IQ scores as well. Ball and Daly's recent analysis of father involvement in Canada (2012) provides extensive new coverage of the diversity of current paternal participation: Allen, Daly, and Ball (2012, Chapter 3) review the fatherhood literature and assert the salutary developmental influence of father engagement.

Grandfathers have been even more neglected in the family research literature (Scraton \& Holland, 2006; Smorti, Tschiesner, \& Farneti, 2012). The analysis of their contributions has been formed in part from the paucity of fatherhood research; but it has also been contended that a feminised perception of grandparenting has hampered a full appreciation of a grandfather's role (Mann, 2007)

We have investigated the healthy functioning of 30-month-old toddler girls (Gillen $\&$ Cameron, 2010) with respect to their emotional security, their use of humour to navigate family engagement, their symbol system development (especially in the context of joint book reading and drawing), their utilisation of safe domestic places for playing, their eating events, their musicality, and their agency (Cameron, Kennedy, \& Cameron, 2008; Cameron \& Pinto, 2009; Cameron, Pinto, Accorti Gamannossi, Hancock, \& Tapanya, 2011; Cameron, Tapanya, \& Gillen, 2006; Gillen \& Hancock, 2006; Hancock, Cameron, \& Talay-Ongan, 2013; Pinto, Accorti Gamannossi, \& Cameron, 2009; Young \& Gillen, 2007, respectively). We have primarily focused on the children themselves and their strengths in interaction with siblings and caregivers. In this paper we investigate certain exchanges of these young girls (also representing a regrettably understudied population, Cunningham, 2006) with their fathers and in certain instances with their grandfathers. Sameroff (2010) views such exchanges as potentiate change between interactive partners as transactions.

For some decades now researchers have studied the development of affective bonds in infancy and early childhood (Cameron et al. 2006; Grossmann et al., 2002; Newland, Coyl, \& Freeman, 2008; Ramchandani, Van IJzendoorn, \& Bakermans-Kranenburg, 2010) and have established the critical importance of early nurturance of caregivers to the emotional security of the developing young child, and especially little girls. Caregiving characteristics of suitable nurturance that are facilitative of affective relational 
well-being are responsiveness, sensitivity, and consistency. It is these characteristics that we looked for in their transactions with the toddlers studied here. Indices of secure attachment relations include a balance between the capacity of seeking support from caregivers when emotional regulation is required and independence striving when safety in environmental circumstances is assured.

Our methodological approach to the investigation of relationships between female toddlers and their fathers/grandfathers involves a filmed Day in the Life (DITL) of each of the four girls in four locations around the globe. (We have, in fact, studied seven children to date but select these four as they serve to provide readers with a sense of cultural difference.) Disheartened by a Eurocentric approach to human development in much of the psychological literature (with only a few notable exceptions like Fleer, 2010; Gillen \& Cameron, 2010; Tudge, 2009) we sought out children in contrastive majority world locations: Thailand, Peru, as well as in minority world contexts of Italy, and the UK to give some breadth to the range of contexts observed. While the research focus is on the child, in every case, a father and in three cases, a grandfather was in the home and sometimes in the video frame for at least part of the investigated day. This quasi-ecological study takes into account the transactions between the young girls and their paternal relatives in the context of the material, social, and familial ethos in which each child is growing. We therefore seek to provide qualitative depth of understanding of the relationships between these toddlers and their male caregivers.

\section{Methodology}

\section{Participants}

Four thriving 30-month-old girls from very different locations around the globe were recruited for this visual socio-ecological study. As indicated, all were girls because the experience of early female development is understudied (Cunningham, 2006). These children were videotaped at home for an entire Day in their Lives. The methodology for the research is described in Gillen et al. (2007).

Beatrice commences her day with her father attentively caring for her in a small flat in northern Italy. Her mother is at work for the first several hours of our investigation. Father spends his time fully engaged with Bea. Although he often defers to her mother on her return from work, he also seems very comfortable assuming the lead in many subsequent transactions throughout the day.

Jessica in the UK is a twin and her parents both have retired parents, who alternate weekly living with them, as not only do they have these two-year-old toddlers, but they also have a one-year-old younger child. The early part of the day sees the three children and their parents and maternal grandparents attending to the children's needs. Before father goes to work, he spends time drawing at the breakfast table with Jessica and her brother. During the rest of the day grandfather serves as backup to all the activities primarily organised by Jessica's mother and grandmother.

Juanita was studied in her extended family's home in a mountain village in Peru (Rex, 1992). Her mother runs a shop and bakery that sustain an entire multigenerational family. Her aunt, her mother's sister, is her primary caregiver during our day of filming. Her mother and maternal grandmother are also major carers, but her father and maternal grandfather were supportive interlocutors during the day as well.

Gai lives next to an extended family compound in northern Thailand in a small separate house with her mother, father, and older sister, situated on the perimeter of the 
home of her paternal uncle and aunt and their family, and her paternal grandmother and grandfather who also live in the compound. On the day of filming Gai's father is at work for the majority of the time, and she is primarily cared for by her mother, her aunt, and her grandmother; but her grandfather is a quiet presence in the activities of the day particularly when he delivers a frog that he finds in his shoe into the courtyard, to the fascination and delight of Gai and the other young children in the homes.

\section{Procedure}

One DITL of each of these little girls was filmed (as described in detail in Gillen \& Cameron, 2010). Families were identified as having thriving 30-month-old toddlers by developmental psychologists in their communities. Parents were contacted and invited to participate in the study and the details of the extensive involvements of the family were carefully described to them, especially as somewhat invasive visual methods were involved. Ethical considerations for privacy and freedom to withdraw or stop the camera at any time were discussed. Once informed consent was obtained, family interviews were conducted, inquiring as to their perspectives on child rearing, family histories, and demographic information was ascertained. A date was set at the families' convenience when two researchers could film and take field notes during an entire day. The local investigators and at least one distal researcher, that is, an investigator at one of the other international team's research sites viewed the footage of the day. From the full day a half-hour compilation video of approximately six five-minute segments was created and shared with the child's family and comments were invited as to their perspectives on the day's events, and the child's situation and transactions within the family. The discussion typically devolved into an exchange of further information of family perspectives on child rearing, youthful thriving, and the particular developmental strengths of their child. The interviews were transcribed (and translated into English if needed) by the local researcher in each global site and the verbal exchanges in the footage of the videos was transcribed for accessibility to our international team, though the indigenous researcher in each location took the lead in segment selection and analysis. The interpretations of each segment are based upon a grounded examination of the observed interactions between participants in the video data in the context of the interview materials gleaned from the families and an insider understanding of the cultural perspectives regarding early experience in that location.

\section{Findings}

Segments of the day were selected for inductive analysis for this paper to offer as broad a range of examples of toddler-grandfather/father transactions as our data set provided. They were not selected to afford cross-cultural comparisons or to claim typicality, which is to say, claims of generalisability on cultural or other grounds would not be warranted. They are presented to facilitate articulating a multiplicity of possible models of masculine nurturance that might broaden and nuance future conceptualisations of fathering (Frascarolo, 2004; Paquette, Bolté, Turcotte, Dubeau, \& Bouchard, 2000).

\section{Bea in Italy with her father}

In order to explore fathers as representatives and as mediators of family values from an international perspective, we first adopted observation of the everyday activities of one 
middle-class, dual-income Italian family: Beatrice and her parents live in a major northern city, where both the mother and the father teach music in the local Musical Lyceum. The family lives in a small urban flat where there is an abundance of toys, books, and musical activities available. She appears comfortable in the care of either parent, spending a substantial amount of time in the company of her father early in the day of our observations. Later in the day, both parents are engaged with the child. Analysing the DITL Italian data, we find various episodes in which the father interacts with Bea: We choose an eating episode, given the high potentiality of eating practices to provide the context for rich affective exchanges, especially in Italy (Gillen \& Hancock, 2006; Pontecorvo, Fasulo, \& Sterponi, 2001).

\section{With FATHER in the kitchen}

The eating event, the midday meal, takes place in the kitchen: Bea is sitting in her small chair safely anchored to the kitchen table. Lucia, her mother, has cooked pasta for Bea, and is now preparing food for the adults' meal. We thus observe the father, Claudio, who engages in childcare alongside the mother: The episode shows how father actively participates in childcare activities, contributing to the child's development and adjustment.

In the selected sequence, Claudio guides Bea's meal, talking with her and encouraging her to feed herself using a fork. He assists Bea, showing her how to handle the fork and how to blow on the pasta to reduce its heat. The way in which the father prepares and serves Bea her food provides insight into how he comfortably accepts his performance of tasks traditionally attributed to female caregivers. Claudio serves as a support and guide for the child during her activities at home mainly through a frame of explicitly ascribing meaning to what he does with Bea, naming objects and actions, commenting on their properties and functions. Father explains his own actions: 'Look, Bea, I'm putting cheese on the pasta, to make it more tasty!' He comments on activities as they are carried out.

In the passage investigated here, he transmits to Bea cultural expectations of the fundamental role certain artefacts play in his actions and how these expectations are also important to how a two-and-a-half-year-old child is expected to enjoy eating. If we focus on language use, we see that the conversations between father and Bea provide the child with reasons for which various items (fork, dish, cup, etc.) and gestures are included too: i.e. 'Please, Bea, take the cup with two hands, to make you sure the water will not pour out...' 'Look, Bea, you do have to blow, otherwise the pasta will be too hot!' The father provides Bea with his particular repertoire in terms of the rules, words, and concepts that are relevant within the particular practice in which they are involved.

The interaction between Bea and her father during the mealtime also shows an overall organisation (Ochs \& Izquierdo, 2009) in which much turn taking is present and father actively promotes processes that stimulate Bea's knowledge and opinions: Claudio tastes the food, expressing appreciation and Bea feeds him some of her pasta, smiling and laughing. By the attentive way his body and his gaze are directed, the father clearly shows his role as active partner in socialisation.

Bea and her father jointly produce a meaningful, coherent episode of 'nurturing and being nurtured'. A configuration emerges in which the two partners are active together, with highly interactive availability: the father clearly focuses on the meal, and he and Bea share a common focus on the same centre of interest. 


\section{Jessica in the UK with father and grandfather}

\section{With FATHER at breakfast play}

Mother Rachel, father Paul, and the three children are at the breakfast table. As well as food, there is a toy fire engine, a soft black and white mechanical toy cow that speaks, small cars, colouring pencils, plus paper. Mother has prepared the table in this way. Father arrives carrying a toy fire engine. He starts drawing a tractor for Jessica on her blank paper whilst her brother Matthew watches, but he too has a blank sheet of white paper. Younger child Alison watches both siblings as her mother feeds her. Jessica is eating her cereal. Father echoes and extends her comments: Jessica says 'And a trailer' and dad says 'A tractor and a trailer'. As her father draws, Jessica communicates, sometimes with comments and sometimes suggestions, 'and a big fat wheel'. Matthew is now drawing but also copying what his father is drawing. As the drawing progresses, Dad reminds Jessica that she is eating her breakfast cereal. He sometimes feeds her whilst she draws. He then turns to Matthew and assists his drawing in a similar way while Jessica concentrates on eating. He asks her if she has finished and watches her get down from her chair, offering her the toy cow, which she carries out of the kitchen.

\section{With GRANDFATHER at the shopping mall, on the wall}

Jessica walks along a low tree- and shrub-containing wall holding her grandfather's hand. He assists her when needed but also gives her scope to walk and balance for herself. He uses language to confirm and reassure and to direct her behaviour. 'All right then ready - jump!' 'Careful now, careful - oh very good'. She holds her plastic bag containing a toy dinosaur on her left shoulder with her left hand across her chest. 'I've got my bag', she says. 'Yes, you've got your bag', says grandfather. 'Big jump now' (as she comes to the end of the low wall). 'Ooo, that's it (as she successfully jumps to the ground). And coming to the end of the next section of the wall, 'I'm gonna jump'. 'All right, ready - jump'. He helps her up onto the wall but she independently jumps off. As though that was a rehearsal, she then walks along the wall completely on her own (without her bag) and thus having two hands to climb up and two to help balance as she jumps off. She negotiates over-hanging plants still maintaining her balance. She notices the escalator and walks to it holding grandfather's hand. 'You're going up on the escalator are you?' 'Yes', says Jessica. 'We'll wait for mummy', he says. After a few seconds the rest of the party arrive and they walk along together; Jessica is still holding grandfather's hand. On the way out of the mall Jessica walks on the same stretch of low wall unaided. Her independent self is comfortable in the scaffolded contexts of her caregivers' support that provides opportunities for exploration and mastery. Shopping mall wall-walking seems to be a skill that Jessica has acquired from other mall visits. Grandfather provides measured support to enable the skill to be practised/further acquired and generally affords her much independence. Flouri (2005) described fathers in the UK as playing a crucial role in child development and subsequent adult status and behaviour.

\section{Juanita in Peru with father and grandfather}

Juanita and FATHER

Juanita awakens to her father Cesar's ministrations. He brings her breakfast to eat in bed, along with toys and other objects that he apparently knows will interest her: a 
shelf upon which to organise toy dishes, and other objects, a balloon, and small stuffed animals. The morning gets off to a less than perfect morning in that Juanita's favourite playmate, her six-year-old cousin Ana, is not well so some of her favourite games have to be held in abeyance. (She does spend the day periodically attempting to seduce Ana into play and is occasionally partially successful but this success is often followed by Ana's subsiding into her own and pleading for rest.) So father has to 'do' as a playmate and carer as mother, Luisa, is at work downstairs in the family shop. Juanita spends some considerable time (10 minutes) organising the materials her father has provided for her entertainment into rows and stacking them on the shelf he has also provided. Her organisations were notably similar in orderliness to her mother's neatly managed and orchestrated shelving in the shop below.

It is notable that Juanita's father seems very well prepared to engage as play resource provider, audience, and supporter for a long and quite uninterrupted period of time. He feeds her breakfast in bed but also chooses toys and activities she revels in: Organising toy dishes on a little shelf, dancing with a balloon in hand (when one balloon pops, her father provides another and he also plays the necessary music for her to dance to, and even videotapes her dancing).

One fact upon which the family is unanimous is Juanita's dancing prowess. Her very rhythmic traditional 'saya' dancing is casually interspersed with her eating breakfast; her father puts on music and encourages her to dance on the bed between other activities. This she does readily and repeatedly, sometimes swinging a balloon on a stick to the music (again for more than 10 minutes at a time).

Once breakfast is finished and she has spent almost one and one half hours playing, her father, as caregiver, gets her dressed and takes her downstairs to the corner shop where her mother has been baking bread and serving customers all morning. Juanita is a later-life child of her mother who also has a much earlier-born adult child and she entrusts this child to the care of father, maternal aunt Lina, grandma, grandpa Lucho, and other available, engaged family members. Father leaves once his daughter is in the shop.

Juanita spends 45 minutes behind the counter in her mother's shop entertaining herself until her aunt comes to take her to her part of the family compound where she feeds her lunch. After 10 minutes of eating by her auntie's spoon, and when Lina can convince her to eat no more, she takes Juanita to her grandfather to complete the job of feeding her lunch for a final 5 minutes.

\section{Juanita and GRANDFATHER acting out 'eating' together}

The exchange between the child and grandfather is warm, quietly vigilant, and though relaxed, far from disinterested. Although her grandfather is miming feeding Juanita, it appears that he has witnessed her adequate previous feeding and he takes his role in completing the meal somewhat lightly and the exchange involves no coercion. When interviewed Grandfather offers firm opinions on the socialisation of children, in particular, their moral education, and has an engaged knowledge of and pride in Juanita's strengths that he wishes to promote especially in her musicality and dancing prowess. Both father and grandfather demonstrate throughout the day and in their interview responses to the investigators a strong investment in Juanita's healthy development and an acute awareness of her skills, interests, and capacity for self-regulation. Juanita is developing her own path towards balancing connection on the one hand and independence on the other (Gillen \& Cameron, 2010, Chapter 8). 


\section{Gai in Thailand grandfather and father}

Fathers in Thailand have been reported (Tulananda \& Roopnarine, 2001) to be less likely to be involved with children than mothers in their culture. However, in an earlier study, while Thai fathers were less likely than American fathers to be involved in childcare, Thai fathers more likely to receive support from extended family members and institutional sources for involvement in childcare than were American fathers (Tulananda, Young, \& Roopnarine, 1994). Cameron (2011) recently reported few differences between Thai mothers and fathers in parenting attitudes and attributions.

Father Chai is at work all day but Gai, being well aware of his absence, does ask for him on several occasions as everybody else is home, it is just that her father's business has not released him for this holiday vacation day. In the home there are many females: grandmother, two mothers (Gai's and her aunt), her sister, and two other school-age cousins, her aunt's daughters.

\section{Gai and her GRANDFATHER's frog}

But also around the family compound all day is the grandfather Boonsom, who is a quiet presence, but nevertheless makes himself available when asked to engage as an 'assistant' in childcare. At one point in the afternoon, grandfather must have wanted to have shoes on, as he put his foot in a shoe and swiftly withdraws it because there is a frog in it. Rather than lose an opportunity for explorations of natural creatures, as a resource provider, he delivers the shoe to the centre of the cousins' activities. They carefully place the shoe on the ground, and all gather round to witness the progress of the frog from this position in the shoe. After considerable time, it is agreed that the frog is not going to move voluntarily so mother Siriwan is urged, by the older children, to drop the animal out of the shoe, which she does to protesting screams from Gai. The frog seems in no hurry to move so they return it to the shoe where everybody seems more comfortable having it rest.

\section{Gai when her FATHER comes home}

A high point of her day is when father, the primary economic provider, returns home from work. All members of the family join around him and after some greetings the family migrates to the sitting room where the television set is turned on and the family sits together watching a documentary programme on wild animals. Dinner is cooking and a meal is served with father the head of the configuration.

Although it has been observed that Thai fathers have tended not to be so involved as mothers in the daily care of children, the current economic situation requires one or both parents to work long hours and this seems to further accentuate the father's lack of participation and results in a traditional division of parent labour. In cases where the extended family is still available, such as in the case of Gai, grandfather or both grandparents help to fill the void. However. as urbanisation has been on the increase, more and more families lose this valuable opportunity, as they become nuclear families instead. However, in the context of an extended family, and indeed in the situation of living in a family complex, Gai finds security in multiple inputs beyond father and grandfather and multiple paths for exploration are possible for this young Thai girl. 


\section{Discussion}

As recently reported in Section 2 of Ball and Daly's (2012) edited book, the story of father involvement is a diversified, consistently renewing, and transformative narrative. Youthful fatherhood, aboriginal fatherhood, divorced fatherhood, fathers on welfare, and fathers of children with chronic conditions are not addressed here, but we have seen considerable diversity in the transactions of the toddlers and their fathers and grandfathers that we have observed. We can stress the relevance of culture in current expectations of what might be expected in fatherhood and provide hints from this exploratory work as to future directions for research on fathers and grandfathers.

In Italy with Bea, in the observed situation the father chooses to function in actions historically perceived as feminine, and he is clearly under his wife's near-by guidance throughout. Father and child dynamically construct the event, as members of that specific social configuration in which the dyad performs social acts, in apparent accord with the other member of the family's (namely, the mother's) everyday expectations. The father seems to conform to the family requirements and the child comfortably recognises and responds to his actions. The mother does not assist, respecting the father's primary role attributed to him in the context. The father independently decides how to feed Bea, directing with a certain degree of freedom the events connected to the meal; but this independence may, of course, have been developed by taking into account how his wife approaches a caring role and vice versa.

Nevertheless, he appears to keep in mind that the father-child dyad is part of the father-mother-child global family system. This emerges from frequent mentions of the mother's contribution to the quality of the food Bea is eating and to the fact she is in the meanwhile preparing food for dinner: Lucia, preparing the food to be put in the oven, comments, 'How crazy I am! I forgot to put the salt!' and Claudio says, smiling to Bea: 'Mami is very able in preparing the sauce!' His behaviour is also confirmed in the mother's actions: she asks him about the amount of pasta Bea has eaten, and appears confident in Claudio's answer: 'Enough!' according him the status of arbiter of the family's values and standards. From this, and from his engagement in the child's feeding it would be possible to imagine that the father perceives himself as a person capable of shouldering both typically masculine as well as typically feminine gender roles, keeping a broad perspective on the integration between his and the mother's role. Father's words often address Bea's concerns, flexibly orienting his actions on her possible intentions or needs. And Bea is offered the opportunity to accept or to refuse father's suggested practices, as when Bea shows her tiredness, repeatedly rubbing her fists on her closed eyes, Claudio, with a tender voice, suggests she will be soon in her 'soft little bed'. During this exchange, the father leans in towards Bea and they look into each other's eyes during their verbal interchange. Here one observes that both members of the pair are attuned on an affective level. Attachment security (Cameron et al., 2006) can be assumed.

The fatherhood we document in Italy demonstrates an affective attunement to the child that implies the presence of that 'emotional' intelligence, traditionally considered as an exclusively feminine trait. The father's presentation to the observers of himself and of his role seems to represent his positive relationship both with the mother and with his child. Overall the qualitative analysis of interactions shows how this Italian father is an active partner in different activities at home: we can see how Bea and her father jointly construct the feeding sequence suggesting how fathers' ways of 
cooperation in family routines have changed over time in Italy. This father actively functions within the family and gets involved in the development of his child's personality and relational capacities, which according to these parents had previously been regarded in their families of origin as an exclusively maternal domain (Arcidiacono, Giorgi, Padiglione, \& Pontecorvo, 2007).

Recently, within the Italian context, some psychological studies have emphasised a progressive shift from a profile of the detached and absent father embodying power and family authority, and confined to the role of economic provider, towards the idea of a 'new father' (Arcidiacono et al., 2006). According to these researchers, fathers' positioning over recent decades is characterised by a transition from a traditional fatherly image as provider to a more modern function as collaborator within the family, although this new image of fatherhood derives from a process that is still perhaps in the making (Ficeto, 2000; Scabini, 2000).

A comparative study conducted among Italian and US families (Klein, Izquierdo, Bradbury, \& Arcidiacono, 2005) revealed that many Italian fathers are rather active in getting breakfast and dinner ready, showing an attitude of reciprocity in their relationships with their partner. More recently, Arcidiacono and Pontecorvo (2010) observed that Italian fathers they studied

actually take on manifold positions within the family participation structure. For example, if we pay attention to the way in which Italian fathers act as partners and even as actors in family cooking duties, we can refer to a previous study of Italian dinner conversations (Ochs, Pontecorvo, \& Fasulo, 1996) that shows a primary maternal dominance in Italian family matters. This evidence of her central role as a mother-figure is perceived as decisive in planning, choosing, and cooking meals, linked to the fact that mothers know better children's tastes and in general children's lives. However, in looking carefully at our present data, we find that the above presented Italian fathers that we observed during few whole days of domestic life are collaborative in cooking duties and sometimes appear as being really experts in the field. (p. 468)

In the UK, all three children in the participating family seek to be very close to their father early in the day - almost as though he is their protector - but this is understandable given two strangers were in the house filming them. Father thus takes on a reassuring role and responds to their needs. At the breakfast table: There appears a family 'practice' evolving, something that has doubtless happened before at breakfast - the integration of father's involvement in drawing, discussion, and about drawing and the drawings and the food as a family breakfast very slowly progresses. Dad is helping the twins to draw for themselves but also seemingly involved in the drawing for himself. This provides an integration of play activities whilst the children eat, and Alison, who is being fed by mum, observes this practice. However, ostensibly breakfast, to the children, this is probably seen as a drawing activity, with the occasional eating of food. For the parents, as they reported to us, this is a way of ensuring that the children eat rather than seek to leave the breakfast table to attend to their play.

The themes arising from the UK footage include the father's preparedness to be a patient observer of his children and not to rush in to solve problems for them; his ability to help them work co-operatively together when a conflict is brewing; his creative use of language to facilitate child action and their desires. The grandfather, for his part, seems comfortable in his apparently ascribed role supporting the activities of his daughter and wife in organising the children's day and in serving as a reliable backup to their plans. This backup includes his patiently supporting the initiatives of the children, 
not interfering in their efforts at self-sufficiency, and withdrawing engagement as the case might demand.

In Peru, father takes care of Juanita while her mother works in the family shop downstairs. He is attentive and it is unclear as to whether he does this child minding on a regular basis or if he was using the occasion for a connection with the foreign guests of the family. Juanita is responsive to her father's ministrations on many occasions but she also sometimes refuses his offers of support and he acquiesces. The technological amenities of the home such as a camcorder are unusual for a family in such a small remote mountain village perhaps signifying the success of mother's shop. Several family members contribute to its smooth operations, especially including her mother's sister and her father as well. Whether Juanita's father is so engaged might also depend upon his prioritising the necessities of his family responsibilities and those of his role as the father of a small child. While the father takes care of his child for much of her morning, his engagement is more custodial and responsive than instrumentally guiding.

Grandfather has few occasions for face-to-face interactions during the day and the responsibility accorded him to complete feeding Juanita her lunch seemed somewhat ceremonial in that she had already eaten a good meal with the support of her aunt and cousin (Gillen \& Hancock, 2006). In handling this duty, grandfather gently goes through motions of feeding Juanita but, basically, engages her in companionable conversation and is supportive of her preferences for activities. He may even be aware that another meal will be served when she rejoins her parents when they take their lunch break. His wise interaction seems to represent a comfortable bond between them. There seems little need in Juanita's day for coercive engagement. Her comfort in her environment reflects these relationships with her caregivers, perhaps reflecting a 'new fatherhood' in Peru as well (Dearden et al., 2013), perhaps a 'generative fathering' (Taylor \& Behnke, 2005), as in Italy and the other locations we have observed in our study - namely, Turkey, and the USA.

The roles of father and grandfather in the Thai family are rather ephemeral in our, albeit, small amount of data. It is certainly the case that Gai called for her father on several occasions during the day. This might have been because although it was a statutory holiday so all the rest of the extended family were at home that day, her father's place of employment had (atypically) not released him so the presence of all the rest of the family without her father might have felt anomalous to Gai. In any case, she noted and seemed to miss his presence. When father returned home there was little interaction between father and child as the television set was immediately turned on and the family sat with it for the rest of the day together. Grandfather was also a quiet presence during the day. His contribution of the frog found in his shoe was a notable exciting exception. This event set the stage for much engagement and an opportunity for several natural experiments, which were monitored by the women in the family, most notably Gai's mother. It would appear that on the basis of the footage of the day, the male parental roles remain quite traditional, giving over the majority of the nurturance and stimulation to the female caregivers. This is not to say, of course, that this family represents a typical Thai family, but does indeed instantiate the continuing presence of such a family functioning model.

When Tulananda and Roopnarine (2001) observed everyday activities of mothers and fathers in Thailand, mothers engaged in basic care, general conversations, and educational activities; praised; and used commands and reasoning more than did fathers but parents did not differ in affection displays, teasing, or play interactions with their 
children. Parents treated boys and girls similarly and there were few associations between parent-child involvement and preschool social skills of Thai children. It is possible that this pattern holds in our focused case study reported here.

Our observations of one father in each of the four case studies and one grandfather in three of them seem to represent notable, albeit somewhat slight, ongoing changes in the assumed role of the fathers towards more complex and multi-faceted functions today. Our findings thus can be seen to contribute to existing understandings about how male caregivers interact with young children but more studies are wanted. We need enlarged perspectives on the roles of fathers and grandfathers in the twenty-first century that takes the perspectives of the male carers (Mann, 2007; Nielsen, 2006; Scraton \& Holland, 2006) and their potentials to affect development through positive transactions. We therefore join Evans and Jones (2008) in their call for renewed efforts to identify the roles of male caregivers both in the home and in early childcare centres to enhance further their clear potentials for positive impacts on the development of young children. Daly and Ball emphasised 'the importance of going beyond monolithic thinking of what constitutes 'father involvement' to demonstrate the importance of father involvement as a complex and contested set of constructions, values, and behaviours that are emerging in response to changing social, political, and economic conditions' (2012, p. 224). Research, theoretical analyses, social policies, and practices call for nuanced examinations of men's roles as fathers and grandfathers and important caregivers of young children.

\section{Notes on contributors}

Catherine Ann Cameron is Honorary professor of Psychology at the University of British Columbia and Emerita professor at the University of New Brunswick, Canada.

Giuliana Pinto is full professor in Psychology at the University of Florence, Italy.

Roger Hancock is a semi-retired lecturer/researcher who works as an educational consultant.

Sombat Tapanya is in the Psychiatry Department of Chiang Mai University, Thailand.

\section{References}

Allen, S., Daly, K., \& Ball, J. (2012). Fathers make a difference in their children's lives: A review of the research evidence. In J. Ball \& K. Daly (Eds.), Father involvement in Canada: Diversity, renewal, and transformation (pp. 50-88). Vancouver: UBC Press.

Amato, P. (1998). More than money?: Men's contributions to their children's lives. In A. Booth $\&$ N. Crouter (Eds.), Men in families: When do they get involved? What difference does it make? (pp. 241-278). Mahwah, NJ: Erlbaum.

Arcidiacono, F., Giorgi, S., Padiglione, V., \& Pontecorvo, C. (2007). Appropriations: Dynamics of domestic space negotiations in Italian middle-class working families. Culture \& Psychology, 13, 147-178.

Arcidiacono, F., \& Pontecorvo, C. (2010). The discursive construction of the fathers' positioning within family participation frameworks. Psychological Education, 25, 449-472.

Ball, J., \& Daly, K. (Eds.). (2012). Father involvement in Canada: Diversity, renewal, and transformation. Vancouver: UBC Press.

Boyce, W. T., Essex, M. J., Alkon, A., Goldsmith, H. H., Kraemer, H. C., \& Kupfer, D. (2005). Early father involvement moderates biobehavioral susceptibility to mental health problems in middle childhood. Journal of the American Academy of Child and Adolescent Psychiatry, $45,1510-1520$.

Cameron, C. A. (2011). A day in the life: A new methodology for investigating early childhood thriving and youth resilience around the globe. ISSBD Bulletin, 1(Ser. No. 59), 20-24. 
Cameron, C. A., \& Pinto, G. (2009). Day in the Life: Secure interludes with joint book reading. Journal of Research in Childhood Education, 3(4), 437-449.

Cameron, C. A., Pinto, G., Accorti Gamannossi, B., Hancock, R., \& Tapanya, S. (2011). Domestic play collaborations in diverse family contexts. Australasian Journal of Early Childhood, 36(4), 78-86.

Cameron, C. A., Tapanya, S., \& Gillen, J. (2006). Swings, hammocks, and rocking chairs as secure bases during a Day in the life in diverse cultures. Child and Youth Care Forum, 35(3), 231-247.

Cameron, E. L., Kennedy, K., \& Cameron, C. A. (2008). 'Let me show you a trick!': A toddler's use of humor to explore, interpret, and negotiate her familial environment during a Day in the life. Journal of Research in Childhood Education, 23, 5-18. doi:org/10.1080/ 02568540809594642

Clarke-Stewart, K. A. (1978). And Daddy makes three: The father's impact on mother and young child. Child Development, 49, 466-478.

Cunningham H. (2006). The invention of childhood. London: BBC Books.

Daly, K., \& Ball, J. (2012). Looking forward: Father involvement and changing forms of masculine care. In J. Ball \& K. Daly (Eds.), Father involvement in Canada: Diversity, renewal, and transformation (pp. 224-237). Vancouver: UBC Press.

Dearden, K., Crookston, B., Madanat, H., West, J., Penny, M., \& Cueto, S. (2013). What difference can fathers make? Early paternal absence compromises Peruvian children's growth. Maternal and Child Nutrition, 9(1), 143-154. doi:10.1111/j.1740-8709.2011.00347.x

de Jong, T. R., Korosi, A., Harris, B. N., Perea-Rodrigues, J. P., \& Saltzman, W. (2012). Individual variation in paternal responses of virgin male California Mice (Peromyscus californicus): Behavioral and physiological correlates. Physiological and Biochemical Zoology, $85,740-751$.

Evans, R., \& Jones, D. (2008). Men in caring, parenting and teaching: Exploring men's roles with young children. Early Child Development and Care, 178(7-8), 659-664. doi:org/10. 1080/03004430802351998

Ficeto, T. (2000). Reinventare la paternità. Per una cultura dei nuovi padri. Rivista di scienze dell'educazione, 1, 15-33.

Fleer, M. (2010). Early learning and development: Cultural-historical concepts in play. New York: Cambridge University Press.

Fletcher, R. (2008). The assessment and support of new fathers: Father-infant attachment as a basis for psychosocial assessment and support. Berlin: Verlag.

Fletcher, R., \& Visser, A. (2008). 'Father engagement' in family relationship centres. Journal of Family Studies, 14(1), 53-65.

Flouri, E. (2005). Fathering and child outcomes. Chichester: Wiley.

Frascarolo, F. (2004). Paternal involvement in child caregiving and infant sociability. Infant Mental Health Journal, 25(6), 509-521.

Gettler, L. T., McDade, T. W., Feranil, A. B., \& Kuzawa, C. W. (2011). Longitudinal evidence that fatherhood decreases testosterone in human males. Proceedings of the National Academy of Sciences, 108(309), 16194-16199. doi/10.1073/pnas.1105403108

Gillen, J., \& Cameron, C. A. (Eds.). (2010). International perspectives on early childhood research: A day in the life. Houndmills: Palgrave Macmillan.

Gillen, J., Cameron, C. A., Tapanya, S., Pinto, G., Hancock, R., Young, S., \& Accorti Gamannossi, B. (2007). 'A day in the life': Advancing a methodology for the cultural study of development and learning in early childhood. Early Child Development and Care, 177(2), 207-218.

Gillen, J., \& Hancock, R. (2006). A day in the life: Exploring eating events involving two-yearold girls and their families in diverse communities. Australian Journal of Early Childhood, 31(4), 23-29.

Grossmann, K., Grossmann, K. E., Fremmer-Bombik, E., Kindler, H., Scheurer- Englisch, H., \& Zimmermann, P. (2002). The uniqueness of the child-father attachment relationship: Fathers' sensitive and challenging play as a pivotal variable in a 16-year long study. Social Development, 11, 307-31.

Hancock, R., Cameron, A., \& Talay-Ongan, A. (2013). Agency and children's well-being. In C. L. Cameron \& L. Miller (Eds.), International perspectives in the early years. London: Sage. 
Harmon, D. K., \& Perry, A. R. (2011). Fathers' unaccounted contributions: Paternal involvement and maternal stress. Fathers in Society, 92(2), 176-182. doi:10.1606/1044-3894.4101

Khaleque, A., \& Rohner, R. P. (2012). Transnational relations between perceived parental acceptance and personality dispositions of children and adults: A meta-analytic review. Personality and Social Psychology Review, 16(2), 103-115. doi:10.1177/ 1088868311418986

Klein, W., Izquierdo, C., Bradbury, T. N., \& Arcidiacono, F. (2005). Collaboration and conflict: Insights into the division of household labor among working couples in the United States and Italy (UCLA-CELF Working Paper, 36, Los Angeles, pp. 121-142). New York: Wiley.

Lamb, M. E. (Ed.). (2010). The role of the father in child development (5th ed.). Hoboken, NJ: John Wiley.

Lewis, C., \& Lamb, M. E. (2006). Fatherhood: Connecting the strands of diversity across time and space. York: Joseph Rowntree Foundation.

Mann, R. (2007). Out of the shadows?: Grandfatherhood, age and masculinities. Journal of Aging Studies, 21, 281-291. doi:10.1016/j.jaging.2007.05.008

Newland, L. A., \& Coyl, D. D. (2010). Fathers' role as attachment figures: An interview with Sir Richard Bowlby. Early Child Development and Care, 180(1-2), 25-32. doi:10.1080/ 03004430903414679.

Newland, L. A., Coyl, D. D., \& Freeman, H. (2008). Predicting preschoolers' attachment security from fathers' involvement, internal working models, and use of social support. Early Child Development and Care, 178(7-8), 785-801. doi:org/10.1080/03004430802352186

Nielsen, L. (2006). Fathers and daughters: A needed course in family studies. Marriage \& Family Review, 38, 1-13.

Ochs, E., \& Izquierdo, C. (2009). Responsibility in childhood: Three developmental trajectories. Ethos, 37(4), 391-413. doi:10.1111/j.1548-1352.2009.01066.x

Ochs, E., Pontecorvo, C., \& Fasulo, A. (1996). Socializing taste. Ethos, 61(1-2), 7-46.

Padilla-Walker, L. M., Day, R. D., Dyer, W. J., \& Black, B. C. (2013). 'Keep on keeping on, even when it's hard!': Predictors and outcomes of adolescent persistence. Journal of Early Adolescence, 33(4), 433-457. doi:10.1177/0272431612449387

Pancsofar, N., \& Vernon-Feagans, L. (2010). Fathers' early contributions to children's language development in families from low-income rural communities. Early Childhood Research Quarterly, 25, 450-463. doi:10.1016/j.ecresq.2010.02.001

Paquette, D., Bolté, C., Turcotte, G., Dubeau, D., \& Bouchard, C. (2000). A new typology of fathering: Defining and associated variables. Infant and Child Development, 9, 213-230.

Parke, R. D. (1996). Fatherhood. Cambridge, MA: Harvard University Press.

Pinto, G., Accorti Gamannossi, B., \& Cameron, C. A. (2009). From scribbles to meanings: Social interaction in different cultures and the emergence of young children's early drawing. Early Child Development \& Care, 179(8), 1-19.

Pontecorvo, C., Fasulo, A., \& Sterponi, L. (2001). Mutual apprentices: The making of parenthood and childhood in family dinner conversations. Human Development, 44, 342-363.

Pougnet, E., Serbin, L. A., Stack, D. M., \& Schwartzman, A. E. (2011). Fathers' influence on children's cognitive and behavioural functioning: A longitudinal study of Canadian families. Canadian Journal of Behavioural Science, 43(3), 173-182.

Ramchandani, P., Van IJzendoorn, M. H., \& Bakermans-Kranenburg, M. J. (2010). Differential susceptibility to fathers' care and involvement: The moderating effect of infant reactivity. Family Science, 1, 93-101.

Rex, A. H. (1992). Peru: A country study. Washington, DC: GPO for the Library of Congress.

Sameroff, A. (2010). A unified theory of development: A dialectic integration of nature and nurture. Child Development, 81(1), 6-22.

Saracho, O. N., \& Spodek, B. (2008). Fathers: The 'invisible' parents. Early Child Development and Care, 178(7-8), 821-836. doi:org/10.1080/03004430802352244

Scabini, E. (2000). New aspects of family relations. In C. Violato, E. Oddoni-Paolucci, \& M. Genuis (Eds.), The changing family and child development (pp. 3-24). London: Ashgate.

Scraton, S., \& Holland, S. (2006). Grandfatherhood and leisure. Leisure Studies, 25, 233-250. doi:10.1080/02614360500504693

Smorti, M., Tschiesner, R., \& Farneti, A. (2012). Grandparent-grandchildren relationship. Procedia: Social \& Behavioral Sciences, 46, 895-898. doi:10.1016/j.sbspro.2012.05.219. 
Taylor, B., \& Behnke, A. (2005). Fathering across the border: Latino fathers in Mexico and the US. Fathering, 3(2), 1-25.

Tenenbaum, H. R., \& Leaper, C. (2002). Are parents' gender schemas related to their children's gender-related cognitions? A meta-analysis. Developmental Psychology, 38(4), 615-630. doi: 10.1037/0012-1649.38.4.615

Tudge, J. (2009). The every day lives of children: Child rearing in diverse societies. New York, NY: New Cambridge University Press.

Tulananda, O., \& Roopnarine, J. L. (2001). Mothers' and fathers' interactions with preschoolers in the home in northern Thailand: Relationships to teachers' assessments of children's social skills. Journal of Family Psychology, 15(4), 676-687. doi:10.1037/0893-3200.15.4.676

Tulananda, O., Young, D. M., \& Roopnarine, J. L. (1994). Thai and American fathers' involvement with preschool age children. Early Child Development and Care, 97(1), 123-133.

Van Dijken, S., Van Der Veer, R., Van IJzendoorn, M., \& Kuipers, H.-J. (1998). Bowlby before Bowlby: The sources of an intellectual departure in psychoanalysis and psychology. Journal of the History of the Behavioral Sciences, 34(3), 247-269. doi:0022-5061/98/030247-23

Young, S., \& Gillen, J. (2007). Toward a revised understanding of young children's musical activities: Reflections from the "Day in the Life" project. Current Musicology, 84, 7-27. 